\title{
Internet of Things for Electronic Markets
}

\author{
Gunasekaran Manogaran ${ }^{1}$ • Naveen Chilamkurti ${ }^{2}$ Ching-Hsien $\mathrm{Hsu}^{3,4}$
}

Published online: 12 May 2021

(C) Institute of Applied Informatics at University of Leipzig 2021

\section{Introduction}

IoT is no longer an infancy, indeed it has become the topmost business growth driver across various sectors. These sections present a brief literature on the position of IoT across electronic markets and its evolution. A successful business is one that should evolve rapidly over time (Moore 1993). From a technological perspective, it's the innovative technologies that keep the business applications alive and competitive. The central part of any business model is an innovative technology, where IoT is one such paradigm through which the business applications can evolve over time. IoT in the context of enterprise systems offers concrete business opportunities to the end-users (Haller et al. 2008). But it also includes numerous research challenges in the future arena of the internet. A typical IoT system bridges the gap between the physical world and its associated information systems. The services are offered through smart objects over the internet.

Over the decades, Radio Frequency Identification (RFID) is widely used in business for manufacturing and easier inventory management (Finkenzeller 2010). Here, the key objective

Gunasekaran Manogaran

manogara001@gannon.edu

Naveen Chilamkurti

n.chilamkurti@latrobe.edu.au

Ching-Hsien Hsu

robertchh@asia.edu.tw; ccs@ asia.edu.tw

1 Computer and Information Science, Gannon University, Erie, PA, USA

2 Department of Computer Science and Information Technology, La Trobe University, Melbourne, 124 La Trobe St, Melbourne, VIC 3083, Australia

3 Department of Computer Science and Information Engineering, Asia University, Taichung 41354, Taiwan

4 Department of Medical Research, China Medical University Hospital, China Medical University, Taichung 40402, Taiwan is to physically communicate with objects to improve operational efficiency. This core principle behind the RFID systems has led to the evolution of breakthrough technology called IoT (Chase 2013). Initially, the term smart devices was introduced in the year 1980. Followed by this invention, from the year 1999 to 2009 internet was absolutely a new trend, and extensive research work was carried out under the background of IoT. In addition, from the year 2000, IoT has become a buzzword with widespread applications.

IoT is a network of interconnected devices across the internet with embedded processors and sensors (Gubbi et al. 2013). In general, IoT devices connect to the IoT gateway or edge devices collect data using embedded devices and sensor networks. The data collected from the IoT devices are then transferred into the real-time cloud environment for further processing processes. When it comes to the electronic market, IoT has numerous advantages. Today's electronic markets are facing massive disruptions with IoT technologies (Shen and Liu 2010). The most prominent application of IoT in the field of electronic markets is inventory management. With IoT devices, customers can easily verify the availability of the product through the internet. In the case of the business owners, IoT enables monitoring the product quantity and quality measures. The use of smart devices reduces human errors and improves the availability of services.

In supply chain management (SCM), the application of IoT enables precise tracking of the product with its location, speed, and other essential factors (Abdel-Basset et al. 2018). For every business, especially with electronic markets, personalization based on consumer preferences is of foremost importance. In such cases, the effective implementation of IoT makes the customer experience exceptionally effective.

The other most promising use of IoT in the context of electronic markets includes smart cities (Arasteh et al. 2016). It optimizes the workloads, predicts emerging trends, and offers qualitative services to the end-users. Some of the reasonable examples of IoT in smart city applications include smart energy, smart transportation, smart parking, and many more.

From the overview, it is observed that IoT redefines electronic markets with profound business opportunities. As the 
usage of devices such as sensors, actuators, and smart devices gets explored in a broader term, there is no doubt that the impact of IoT will increase to a greater degree in the coming years. Hence, more in-depth research towards this background has become necessary.

\section{IoT in Electronic Markets}

A short introduction to the list of articles presented in this special issue is described as follows:

The first paper on "Improving business process and functionality using IoT based E3-value business model" is authored by Alaa Shoukry, Jameel Khader and Showkat Gani (Shoukry et al. 2021). They introduce an E3-valued business model to examine the key elements of business, company propositions, distribution channel, and so on. This approach successfully identifies business-related functionalities and improves overall performance measures. The efficiency of this work is evaluated in terms of accuracy, end-user satisfaction, and Pearson correlation coefficient.

The second paper is authored by Sarah Bayer, Henner Gimpel and Daniel Rau and it is entitled "IoT-commerce - opportunities for customers through an affordance lens" (Bayer et al. 2021). The authors present an extensive review and conceptualize IoT-based commerce, find opportunities for customers, and interconnect them to the customer buying preferences. From the observation, twelve affordances are derived and evaluated using the sample of real-time IoT devices. The paper offers insights on situation-aware services, natural interactions, and automated customer processes.

The third paper is authored by Ute Paukstadt and Jörg Becker and is titled "Uncovering the business value of the internet of things in the energy domain - a review of smart energy business models" (Paukstadt and Becker 2021). The prime focus of this work is related to energy business models. The authors carry out an extensive survey to bridge the gaps in the existing literature. They efficiently derive business values from the energy domain with information systems and identify relevant business models and introduce a future research agenda for IoT based energy applications.

Finally, the fourth article is on "Predictive maintenance as an Internet of Things enabled business model: A taxonomy”. Jens Passlick, Sonja Dreyer, Daniel Olivotti, Lukas Grützner, Dennis Eilers and Michael H. Breitner present an interesting predictive model to enhance the performance of IoT enabled business applications (Passlick et al. 2021). From the observation, the outcomes of this research are found to be comparatively satisfactory to the existing systems.

\section{Conclusion}

This special issue brings together significant contributions of IoT in electronic markets. We appreciate the feedback to the special issue call and the many original research contributions that were submitted for consideration. Among them, a total of four articles were selected after the completion of a careful peer-review process. All of the selected articles fulfill the standard quality requirements of the journal and contribute interesting approaches to the research community. We wish to express our sincere gratitude to the Editors-in-Chief for offering us the privilege to edit a special issue in this reputed journal. We appreciate the timely contributions of the authors and reviewers, which has made this special issue a great success.

\section{References}

Abdel-Basset, M., Manogaran, G., \& Mohamed, M. (2018). Internet of things (IoT) and its impact on supply chain: A framework for building smart, secure and efficient systems. Future Generation Computer Systems, 86, 614-628. https://doi.org/10.1016/j.future. 2018.04.051.

Arasteh, H., Hosseinnezhad, V., Loia, V., Tommasetti, A., Troisi, O., Shafie-khah, M., \& Siano, P. (2016). Iot-based smart cities: A survey. 2016 IEEE 16th International Conference on Environment and Electrical Engineering (EEEIC) (pp. 1-6). https://doi.org/10.1109/ EEEIC.2016.7555867.

Bayer, S., Gimpel, H., \& Rau, D. (2021). IoT-commerce - opportunities for customers through an affordance lens. Electronic Markets, 31(1). https://doi.org/10.1007/s12525-020-00405-8.

Chase, J. (2013). The evolution of the internet of things. Texas Instruments, 1, 1-7.

Finkenzeller, K. (2010). RFID handbook: Fundamentals and applications in contactless smart cards, radio frequency identification and near-field communication. John Wiley \& Sons.

Gubbi, J., Buyya, R., Marusic, S., \& Palaniswami, M. (2013). Internet of things (IoT): A vision, architectural elements, and future directions. Future Generation Computer Systems, 29(7), 1645-1660. https:// doi.org/10.1016/j.future.2013.01.010.

Haller, S., Karnouskos, S., \& Schroth, C. (2008). The internet of things in an enterprise context. In J. Domingue, D. Fensel, P. Traverso (Eds.), Future Internet Symposium (pp. 14-28). Springer, Berlin, Heidelberg. https://doi.org/10.1007/978-3-642-00985-3_2.

Moore, J. F. (1993). Predators and prey: A new ecology of competition. Harvard Business Review, 71(3), 75-86. 
Passlick, J., Dreyer, S., Olivotti, D., Grützner, L., Eilers, D., \& Breitner, M. H. (2021). Predictive maintenance as an internet of things enabled business model: A taxonomy. Electronic Markets, 31(1). https://doi.org/10.1007/s12525-020-00440-5.

Paukstadt, U., \& Becker, J. (2021). Uncovering the business value of the internet of things in the energy domain - A review of smart energy business models. Electronic Markets, 31(1). https://doi.org/10.1007/ s12525-019-00381-8.

Shen, G., \& Liu, B. (2010). Research on application of internet of things in electronic commerce. 2010 Third International Symposium on
Electronic Commerce and Security (pp. 13-16). IEEE. https://doi. org/10.1109/ISECS.2010.11.

Shoukry, A., Khader, J., \& Gani, S. (2021). Improving business process and functionality using IoT based E3-value business model. Electronic Markets, 31(1). https://doi.org/10.1007/s12525-01900344-z.

Publisher's note Springer Nature remains neutral with regard to jurisdictional claims in published maps and institutional affiliations. 